\title{
Characterization of a mutant T-cell hybridoma line with defects in the TCR-mediated apoptotic pathway
}

\author{
Grant Morgan ${ }^{1}$, Sallie Smith ${ }^{2}$, John Pak ${ }^{3}$, \\ Ann Marshak-Rothstein ${ }^{3}$, Rafael Fissore ${ }^{1}$ and \\ Barbara Osborne ${ }^{1,4}$ \\ 1 Department of Veterinary and Animal Sciences, Paige Labs, University of \\ Massachusetts, Amherst, 01003, USA \\ 2 Department of Cell Biology, Harvard Medical School, Boston, Massachusetts \\ 02115, USA \\ ${ }^{3}$ Department of Medicine, Boston University Medical Center, Massachusetts, \\ 02118, USA \\ ${ }^{4}$ corresponding author: Prof BA Osborne, Department of Veterinary and Animal \\ Sciences, Paige Labs, University of Massachusetts, Amherst, 01003 USA. \\ tel: (413) 545 4882, fax: (413) 545 6326, email: osborne@vasci.umass.edu
}

Received 30.4.98; revised 5.7.98; accepted 10.8.98 Edited by D. Green

\begin{abstract}
A mutant T-cell hybridoma line named mutant 51 was developed that, unlike the parental line, did not die after T-cell receptor (TCR) engagement and demonstrated reduced death in response to dexamethasone. Intracellular calcium measurements showed that available calcium stores were markedly reduced in the mutant cell line. Unlike control cells, secretion of IL-2 from mutant cells was also greatly reduced, although addition of exogenous IL-2 did not facilitate increased apoptosis. Although levels of the cell death gene product Nur77 were equivalent, additional studies showed that mutant cells expressed Nur77 predominantly in the cytoplasm following TCR engagement, while parental cells displayed a nuclear translocalization of Nur77. In addition, Fas levels and Fas ligand dependant killing were both markedly reduced in the mutant clone. From these data we hypothesize a role for available calcium stores and Nur77 nuclear localization in TCR-mediated apoptosis in T-cell hybridomas.
\end{abstract}

Keywords: apoptosis; T-cell hybridoma; calcium; Nur77; TCR signaling

\footnotetext{
Abbreviations: PMA, phorbol myristate acetate; A23187, calcium ionophore; TCR, T-cell receptor; PBS, phosphate buffered saline; IP3(R), inositol 1,4,5, trisphosphate (receptor); PCD, programmed cell death; $\mathrm{Ca}^{2+}$, calcium; ER, endoplasmic reticulum; NFAT, nuclear factor of activated T-cells; IL-2, interleukin-2; Fas (L/R), Fas/ AP01/CD95 (Ligand/Receptor); SDS, sodium dodecyl sulphate; DTT dithiothreitol; FITC, fluorescein isothiocyanate; DMEM, Dulbecco's modified eagles medium, FACS, fluorescence activated cell sorter; HEPES, hydroxyethyl-piperazineethanesulfonic acid
}

\section{Introduction}

Negative selection of thymocytes demonstrates the classical characteristics of apoptosis, however the molecular pathways initiated during this process are not well understood. In vitro, thymocytes and T-cell hybridoma cell lines provide useful tools to study programmed cell death (PCD) in lymphocytes. Apoptosis can be induced in these cells by synthetic glucocorticoids, ${ }^{1}$ via signals delivered through the T-cell receptor (TCR), ${ }^{2}$ by agents that mimic the action of T-cell receptor engagement (such as phorbol esters and calcium ionophore), or by irradiation. . $^{3,4}$ These mediators of apoptosis have been shown to initiate unique signaling cascades involving pathway specific gene products. $^{5}$

TCR engagement initially leads to a well characterized cascade of events resulting in an early and pronounced intracellular calcium $\left[\mathrm{Ca}^{2+}\right]$ rise. TCR cross linking causes tyrosine kinase activation leading to stimulation of phospholipase $\mathrm{C}_{\gamma}$ and subsequent induction of diacylglycerol and inositol 1,4,5 triphosphate $\left(\mathrm{IP}_{3}\right)$ production. Diacylglycerol then activates protein kinase $C$ that in turn targets several calcium dependent-protein substrates. ${ }^{6}$ Simultaneously $\mathrm{IP}_{3}$ induces a cytoplasmic $\left[\mathrm{Ca}^{2+}\right]$ rise from intracellular stores. Depletion of these stores then signals capacitative $\mathrm{Ca}^{2+}$ influx across the plasma membrane. This influx of calcium into the cytoplasm subsequently activates downstream signaling events. ${ }^{7}$

The essential role of calcium in the apoptotic pathway has been demonstrated in both thymocytes, ${ }^{8}$ T-cells and numerous other cell types. Using intracellular calcium chelators, it has been shown that suppression of TCRmediated $\mathrm{Ca}^{2+}$ rises results in a reduction of apoptosis in T-cell hybridomas. ${ }^{6}$ Calcium has also been suggested to play a role as an early mediator of glucocorticoid-induced cell death and in many other signaling pathways. Thus this ion has a rather promiscuous function in numerous important cellular fates.

Several calcium dependent substrates involved in apoptotic signaling have been identified. The $\mathrm{Ca}^{2+}$ dependent neutral protease calpain has been shown to be involved in glucocorticoid and irradiation-induced peripheral T-cell apoptosis. ${ }^{9}$ Also the $\mathrm{Ca}^{2+}$-dependent endonuclease NUC18 necessary for DNA cleavage to oligonucleosome length fragments requires elevated calcium. ${ }^{10}$ Further, it has been shown that calmodulin, a calcium binding protein, and the $\mathrm{Ca}^{2+} /$ calmodulin-dependent protein phosphatase calcineurin are important in the programmed cell death of lymphocytes. ${ }^{11,12}$

Though all inductive stimuli cause the characteristic signs of apoptosis, pathway specific gene products have been identified that transduce the apoptotic message in response to only one external signal. One such protein is the mammalian transcription factor Nur77, an immediate- 
early gene product and member of the steroid receptor superfamily. This orphan receptor has been shown to be up regulated and absolutely required for both TCR-mediated apoptosis in vitro, ${ }^{13,14}$ and for negative selection of thymocytes in vivo. ${ }^{15}$ In contrast dexamethasone or $\gamma$ irradiation-induced apoptosis neither up regulates nor requires Nur77 expression. Similarly, p53 appears to be required for irradiation induced cell death but is not required for either TCR-mediated or dexamethasone induced apoptosis in thymocytes. ${ }^{3}$

The up regulation of Fas ligand and engagement of the Fas receptor induced by TCR engagement have been shown to be absolutely required for activation induced cell death in mature T-cells. ${ }^{16-18}$ Fas receptor cross linking initiates a well characterized signaling cascade, ${ }^{19}$ that culminates in the activation of a series of unique proteases, termed caspases, that are thought to be the executioners of the apoptotic pathway. ${ }^{20,21}$ In mice lacking expression of either the Fas receptor or its ligand there is little activation induced cell death in their lymphopoietic system and both mice strains eventually develop lymphadenopathy and autoimmune disease as a result of massive, abnormal lymphopoietic expansion. This expansion appears to be due to a failure to remove activated T-cells via activation induced cell death. ${ }^{22}$ However, the importance of Fas signaling in thymocyte apoptosis remains controversial as negative selection is reduced but not abrogated in these mouse strains. ${ }^{23,24}$

To further dissect the mechanism by which thymocytes undergo apoptosis via TCR-stimulated negative selection, the T-cell hybridoma DO11.10 was used to select mutants that did not die in response to phorbol myristate acetate (PMA) and the calcium ionophore A23187, agents known to mimic TCR engagement. One mutant cell line was selected, named mutant 51 , that demonstrated markedly reduced death in response to PMA and A23187. This mutant line and the parental cell line D011.10 were then stimulated to die by various agents and a detailed study of the cellular and molecular consequences associated with the putative apoptotic stimuli were compared.

Here we present data that demonstrate that the mutant 51 cell line was resistant to TCR-mediated apoptosis and partially unresponsive to the glucocorticoid, dexamethasone, while still being susceptible $\gamma$ irradiation-induced apoptosis. Subsequent study of the resistance to TCRmediated apoptosis indicated that although calcium capicitance were comparable in the two lines, calcium stores in the mutant 51 cell line was markedly reduced, indicating the defect affects the ability of the endoplasmic reticulum, the main calcium storage site, to maintain or acquire calcium. In addition, expression of Nur77 protein following TCR engagement was both delayed, and defective in nuclear translocation in the mutant cells in contrast to the parental line. Lastly, we found that levels by the Fas receptor and cytotoxic killing of Fas ligand on the mutant cell line were also both greatly reduced, although interestingly additional studies indicated that direct Fas signaling failed to induce programmed cell death in either the parental or mutant cell lines.

\section{Results}

\section{PMA/A23187 selected mutant 51 cells are highly reisstant to TCR-mediated and partially resistant to glucocorticoid-induced apoptosis, but are sensitive to $\gamma$ irradiation induced death}

Apoptosis can be induced by several mechanisms including TCR engagement, glucocorticoids such as dexamethasone, or $\gamma$ irradiation. Though they all lead to the characteristic manifestations of apoptosis such as membrane blebbing and nuclear condensation, their inductive signaling pathways leading to the execution stage of apoptosis are very different. ${ }^{5}$ Mutant 51 was selected and cloned after repeated exposure to PMA and A23187, agents that are proposed to mimic TCR-mediated apoptosis. Subsequently, it was first determined if the PMA/A23187 non-responsive clone was resistant to all forms of apoptosis. FACScan exclusion analysis using FITC, shown in Figure 1, demonstrates that TCR-mediated cell death was inhibited in the mutant 51 cell line. In contrast, the mutant cells died equally well as the parental cell line in response to $\gamma$ irradiation, suggesting the mutation or mutations do not affect this signaling pathway. In response to dexamethasone treatment, which has been shown to have an antagonistic effect on TCR-mediated apoptosis, there was a significant decrease in cell death in mutant 51 cells although not to the extent seen in TCRmediated signaling. These results suggest that the main perturbance of apoptosis affects the TCR-mediated pathway. In addition signaling molecules common to both TCR and dexamethasone mediated cell death may also be defective.

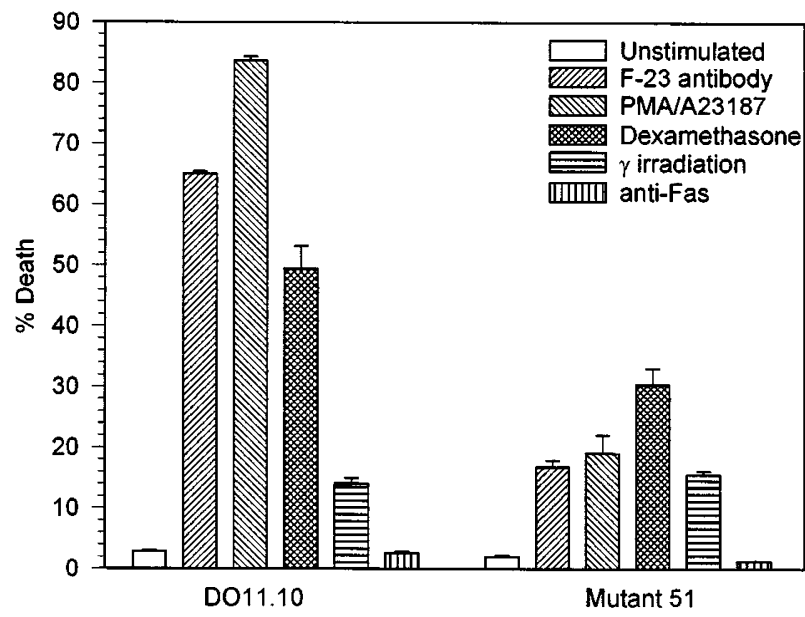

Figure 1 Analysis of D011.10 and mutant 51 cell death in response to multiple stimuli. D011.10 and mutant 51 were seeded at $2 \times 10^{5}$ cells $/ \mathrm{ml}$ in triplicate $0.5 \mathrm{ml}$ cultures for $18 \mathrm{~h}$ in growth medium supplemented with either no treatment (Unstimulated bar), neat supernatant from F23.1 antibody producing cells (F-23 antibody bar), $10 \mathrm{nM}$ PMA + $500 \mathrm{nM}$ A23187 (PMA/ A23187 bar), $10 \mu \mathrm{M}$ dexamethasone (Dexamethasone bar), $30 \mathrm{~Gy} \gamma$ irradiation ( $\gamma$ irradiation bar) or $10 \mu \mathrm{g}$ anti-Fas antibody $\mathrm{J} 02 / \mathrm{ml}$ (anti-Fas bar). Cells were then stained with FITC as described in the Materials and Methods section before analysis for \% death using FACScan and Lysis software (Becton Dickenson). Standard error bars are shown. This experiment is representative of multiple comparable studies 


\section{Intracellular calcium stores are reduced in mutant cells}

As both TCR and glucocorticoid-induced cell death were diminished in mutant 51 , it is likely that a signaling molecule required for both these pathways may be defective. These two pathways utilize different molecules during their inductive stage of the apoptotic pathway so we looked for a signaling event that was shared by both pathways. An early event in thymocyte death is a large calcium rise in the cytoplasm of the cell. Inhibition of this rise has been shown to prevent apoptosis suggesting a direct role of calcium in cell death. To investigate if calcium levels were perturbed in mutant 51 , calcium rises originating from both capacitative entry and endoplasmic reticulum stores were measured using the fluorescent $\mathrm{Ca}^{2+}$ indicator Fluo 3 (Molecular Probes). Thapsigargin was used to assess the level of calcium present in cytoplasmic stores in the absence of extracellular $\mathrm{Ca}^{2+}$. This drug specifically inhibits the calcium ATPase pumps of the endoplasmic reticulum ER, ${ }^{25}$ and in its presence calcium leaks from the ER into the cytoplasm where it induces a $\mathrm{Ca}^{2+}$ rise (Figure 2A). The rise is larger in DO11.10 cells (first Fluo 3 peak, panel a), than in the mutant cell line (first Fluo 3 peak, panel b). This $\mathrm{Ca}^{2+}$ rise in the mutant 51 cell line approximated to $50 \%$ of the DO11.10 controls based on single cell studies (data not shown).

As the capactitative influx of calcium is triggered by the prior release of calcium from the ER, we investigated if extracellular calcium influx into mutant cells was also decreased. These studies used cells previously treated with thapsigargin. Control and mutant cells demonstrated a similar calcium profile following the addition of $\mathrm{CaCl}_{2}$ to calcium free medium, illustrating that the defect does not prevent capacitative calcium entry into the cells (Figure 2A; compare second Fluo 3 rise above baseline in each panel). From these studies we conclude that there is a defect associated with diminished calcium stores in the non-responsive cell line. This lack of available calcium may prevent maximal amplification of the downstream calcium dependent steps required for both TCR and dexamethasone-mediated cell death in mutant 51 .

\section{Inositol triphosphate receptor levels are comparable in both the mutant and parental cell line}

Calcium release from the ER after TCR engagement is mediated by the second messenger inositol triphosphate (IP3) binding to its receptor in the ER membrane causing calcium release into the cytoplasm. ${ }^{26}$ To determine if the diminished calcium release from the ER in the mutant cell line was due to reduced levels of the inositol triphosphate receptor type 1 (IP3R), protein lysates were made from mutant 51 and D011.10 cells after PMA/A23187 stimulation. IP3R1 levels were then detected via Western blot analysis. No decrease was observed in the amount of IP3R1 protein after stimulation to die in mutant 51 cells as compared to the parental cell line (Figure 2B). Thus absolute IP3R1 levels do not explain the lack of ER derived calcium elevation.

\section{Mutant 51 express comparable TCR levels to the parental D011.10 cell line}

Since the greatest inhibition of cell death in mutant 51 was observed via the TCR-mediated signaling pathway (see Figure

\section{A}

a
D011.10 Cell Line

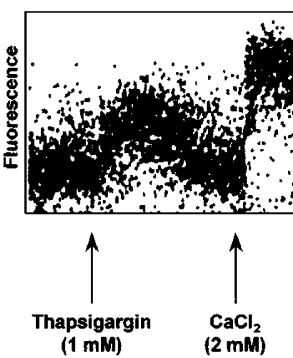

B

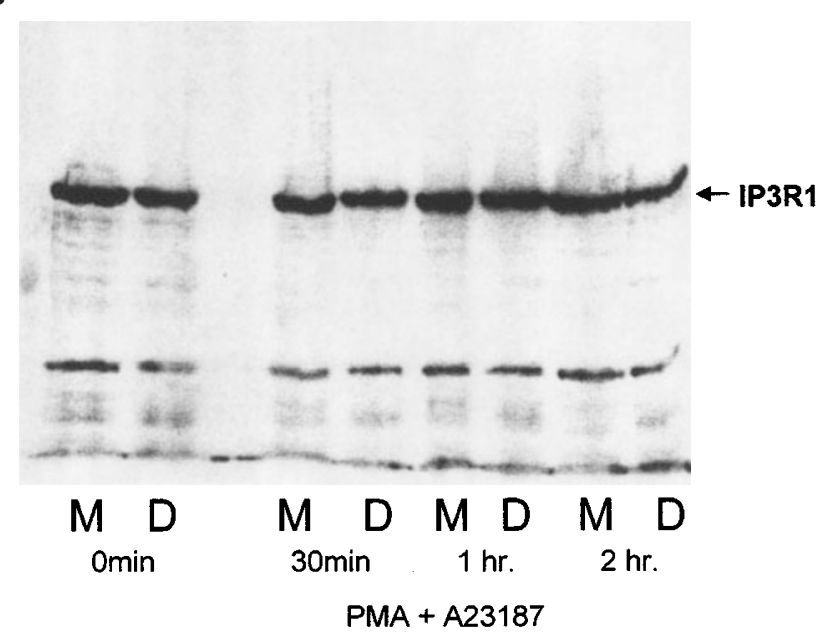

Figure 2 (A) FACScan analysis of intracellular calcium changes in D011.10 and mutant 51 cells. $2 \times 10^{5}$ cells were washed in calcium free medium and incubated with $1 \mu \mathrm{M}$ Fluo 3 (Molecular Probes) and $1 \mu \mathrm{l} / \mathrm{ml} 20 \%$ Pluronic acid (Molecular Probes). After incubation at $37^{\circ} \mathrm{C}$ in the dark the cells were washed in calcium free medium and resuspended in calcium free medium supplemented with $1 \%$ horse serum pre-dialyzed with $6 \mathrm{mM}$ EGTA. Cells were placed on ice until analyzed by FACScan. Before each sample was run it was warmed to $37^{\circ} \mathrm{C}$ then a baseline fluoresecence (FL1) was obtained. Addition of $1 \mu \mathrm{M}$ Thapsigargin caused endoplasmic reticulum calcium stores to empty into the cytoplasm giving a corresponding fluorescence rise. After the cell fluorescence had returned to baseline $2 \mathrm{mM} \mathrm{CaCl}_{2}$ was added enabling capacitative calcium entry to be measured. Results show one of three experimental repeats and are consistent with observations seen in all cases. (B) Analysis of IP3 receptor protein levels by Western blot analysis. $4 \times 10^{5}$ DO11.10 or mutant 51 cells were incubated with $10 \mathrm{nM}$ PMA $+500 \mathrm{nM} \mathrm{A23187}$ for the times shown and then washed in PBS $2 \times$ before resuspension in SDS sample buffer. Proteins were separated in a $4 \%$ (stacking and running) polyacrylamide gel and transferred to nitrocellulose. IP3R protein was incubated with 1:4000 dilution of anti-IP3R type 1 antibodies (a kind gift from JB Parys and KU Leuven, Belgium) followed by $1: 4000$ goat anti-rabbit/ HRP secondary antibodies. Immunodetection of proteins followed directions as described for chemiluminescence analysis using the ECL system (Amersham). Lanes labeled (M) correspond to mutant 51 cell lysates and lanes labeled (D) indicate DO11.10 cell lysates. A polyacrylamide gel was also run to confirm equal loading of protein lysates and was visualized with coomassie blue-equal loading was seen in all lanes (data not shown) 
1) and the number of TCR molecules dictate the amount of signal elicited, the level of TCR expression on the mutant 51 cells was measured. Comparison of TCR levels on nonresponsive mutant 51 and parental DO11.10 cells demonstrated that the mutant 51 cell line expressed a similar number of TCR/CD3 complexes to the parental population (Figure 3A). Thus the non-responsive cells can perceive the ligand for TCR-induced apoptosis but are defective in the TCR-specific downstream signaling events associated with cell death.

\section{Mutant 51 cells do not secrete IL-2 in culture}

Next we investigated whether we could detect additional, or downstream calcium dependent components that were defective after TCR engagement. Signaling through the TCR in DO11.10 cells not only leads to apoptosis but also IL-2 secretion. Consequently we investigated whether TCRmediated IL-2 secretion was affected by the mutation in mutant 51 cells. Control DO11.10 cells produced IL-2 in response to both TCR engagement, or with PMA and A23187 addition. Unlike DO11.10 cells, the mutant 51 cell line under similar conditions failed to secrete this cytokine (Figure 3B), indicating the mutation affects a shared event following TCR engagement. To rule out the possibility that IL-2 is required for equivalent TCR-mediated apoptosis the cytokine was added to mutant 51 cells that had been induced to die by F23.1. No increase in death was observed (unpublished data, SS and GM), demonstrating that the apoptotic defect is not IL-2 dependent.

\section{Mutant 51 cells fail to $G_{1}$ arrest in response to TCR stimulation}

Numerous studies have shown that cell cycle arrest occurs prior to cellular apoptosis, although cell cycle arrest does not obligate the cell to undergo cell death. ${ }^{27}$ DO11.10 cells accumulate in $G_{1}$ of the cell cycle when stimulated to die by antibodies to the TCR (Figure 4). This is associated with a loss of cells from both $\mathrm{G}_{2} / \mathrm{M}$ and $\mathrm{S}$ phases of the cell division cycle. Interestingly, when stimulated by PMA and A23187, D011.10 cells initially arrested in both $G_{1}$ and $G_{2} / M$, with a concomitant loss of cells from S-phase. PMA and A23187 also caused non-responsive mutant 51 cells to accumulate in $G_{1}$ and $G_{2} / M$ of the cell cycle. Therefore, as has been demonstrated previously, cell death is not an irreversible consequence of cell cycle arrest since PMA/A223187 induced accumulation of mutant 51 cells in both $G_{1}$ and $G_{2} / M$ but did not initiate apoptosis. In contrast, TCR engagement of mutant 51 cells caused no arrest in any cell cycle phase (Figure 4). Thus the defect prevents the $\mathrm{G}_{1}$ arrest associated with TCR-mediated apoptosis, but does not inhibit the cell cycle restriction induced by PMA and A23187.

\section{Translation of the apoptosis-associated gene product Nur77 is delayed in non-responsive cells}

We and others have shown the requirement for Nur77 expression for TCR-mediated apoptosis in DO11.10. ${ }^{13,14}$ Consequently we investigated the transcription and translation levels of this gene in the mutant and parental cells. The mRNA transcript levels of nur77 were found to be equivalent in both DO11.10 and mutant 51 cells (data not shown). Therefore Western blot analysis was used to evaluate the levels and phosphorylation states of this transcription factor in mutant 51 cells (Figure $5 \mathrm{~A}$ ). When stimulated through the TCR both mutant 51 and D011.10 cells produced Nur77 but this expression was delayed by

A

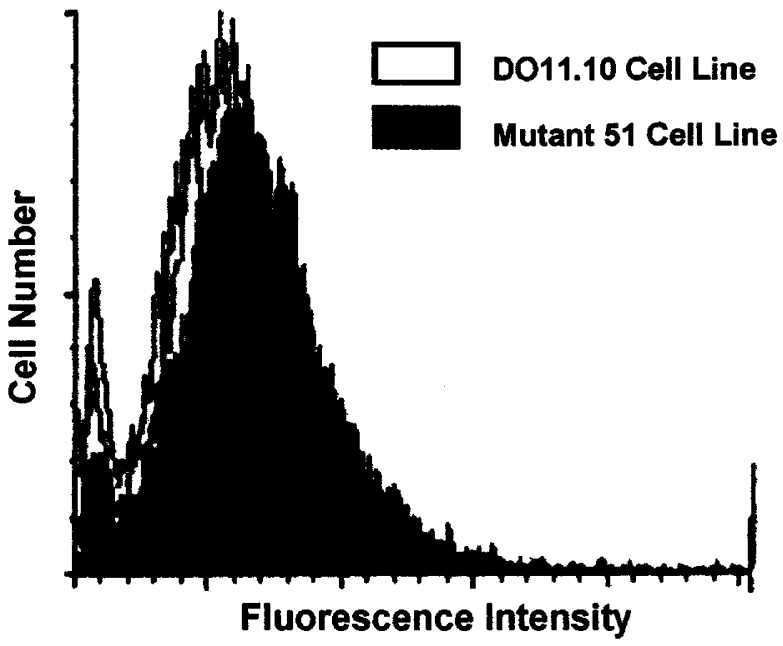

B

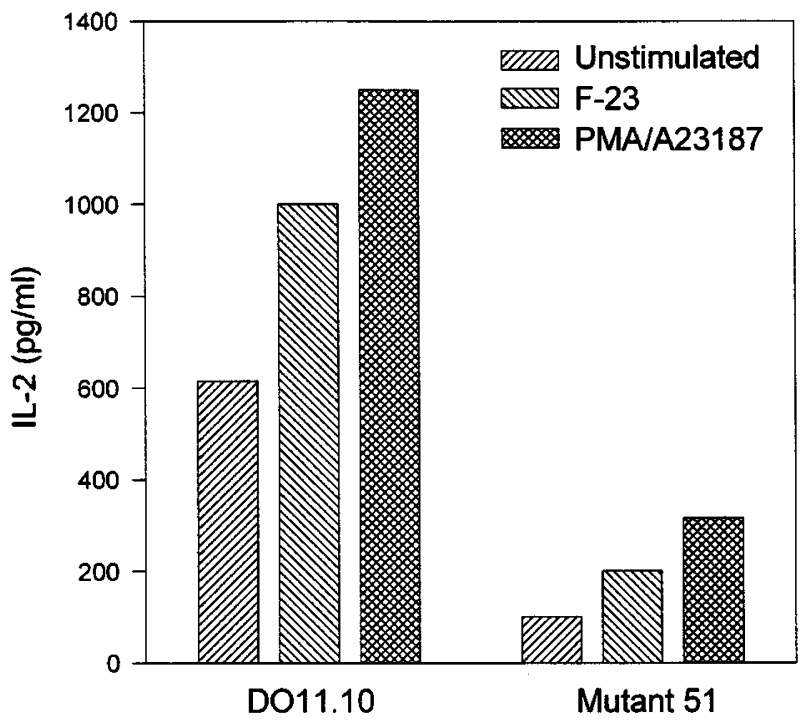

Figure 3 (A) TCR surface expression of mutant 51 and D011.10 cells. Mutant 51 and DO11.10 cells were stained with F23.1 antibody for 30 min on ice. Cells were then washed in PBS and FITC-conjugated secondary antibody added at room temperature for $30 \mathrm{~min}$. Cells were then washed and fixed in $1 \%$ formalin. The cell surface level of $T$ cell receptors was analyzed by FACScan. (B) IL-2 production of DO11.10 and mutant 51 cells. $1 \times 10^{5} / \mathrm{ml}$ cells were stimulated with F23.1 antibody or $10 \mathrm{nM}$ PMA + $500 \mathrm{nM}$ A23187 before analysis. Secretion of Interleukin 2 (IL-2) in culture supernatant was detected using the Biosource International Cytoscreen Immunoassay kit (Biosource). The manufacturers instructions were followed as described and absorbency read at $450 \mathrm{~nm}$. Results are presented as IL-2 produced in pg/ml. This result is the average of duplicate cultures tested and are representative of additional experiments 


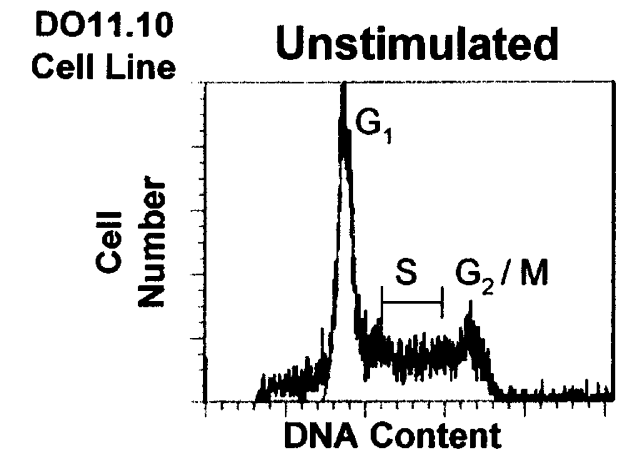

Mutant 51

Cell Line

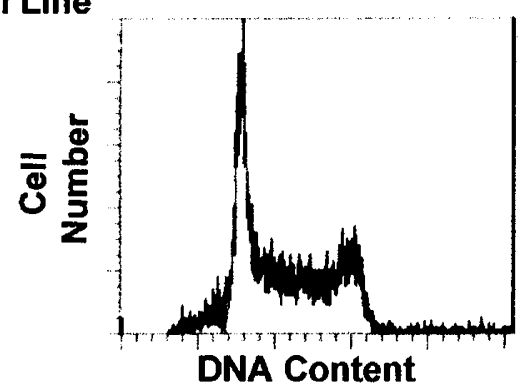

PMA / A23187

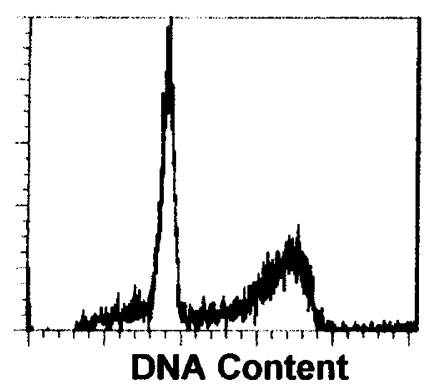

DNA Content

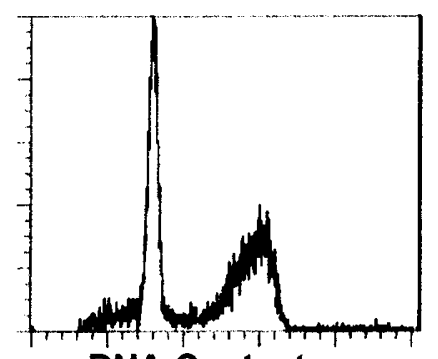

DNA Content
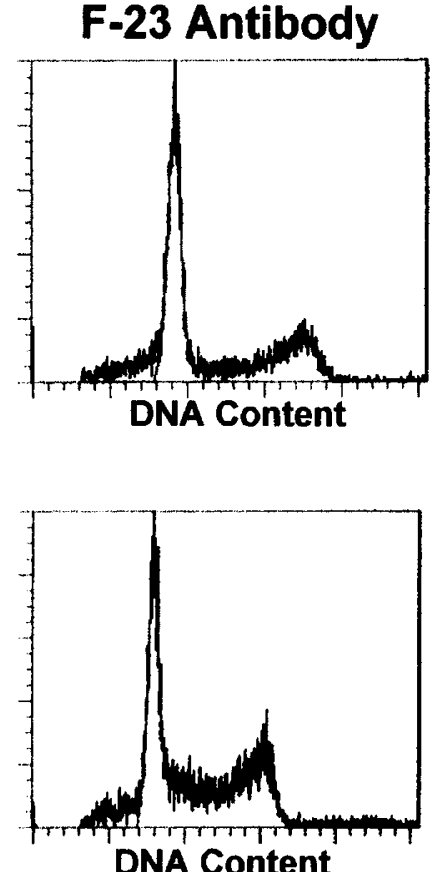

Figure 4 Cell cycle distribution of control and mutant cells. $4 \times 10^{5} / \mathrm{ml}$ cells from mutant 51 and D011.10 populations were cultured in growth medium with or without $10 \mathrm{nM}$ PMA $+500 \mathrm{nM} \mathrm{A23187}$ or F23.1 for $6 \mathrm{~h}$. Cells were then fixed in $70 \%$ ethanol before overnight incubation at $-20^{\circ} \mathrm{C}$. The cells were then washed in PBS before exposure to 50 units RNase and $50 \mu \mathrm{g} / \mathrm{ml}$ propidium iodide. Populations were then analyzed by FACScan using CELLFIT software. Results show the population cell cycle distribution of cells in either the first gap phase with $2 n$ DNA content $\left(G_{1}\right), S$ phase where cells are undergoing DNA synthesis, or in the second gap phase with $4 \mathrm{n}$ DNA content $\left(G_{2}\right)$ or mitosis $(M)$. Results are representative of comparable experiments

$1-2 \mathrm{~h}$ in the mutant cell line. Comparison of levels and phosphorylation states showed a slightly decreased level of Nur77 protein in some experiments in mutant 51 cells but a similar degree of phosphorylation in comparison to the parental cell line (as assessed by band intensity and degree of gel retardation). Following the delayed expression of Nur77 in mutant 51 cells the levels of this protein in both mutant 51 and DO11.10 cells reached plateau at 3$5 \mathrm{~h}$ after TCR engagement and remained relatively constant to $9 \mathrm{~h}$ (data not shown). Similar results were obtained with PMA + A23187 induced Nur77 expression (data not shown).

\section{Nur77 fails to localize to the nucleus in mutant $\mathbf{5 1}$ cells after TCR engagement}

It is proposed that as a transcription factor Nur77 must localize to the nucleus to initiate transcription of downstream genes associated with the apoptotic signaling cascade. $^{28}$ Therefore the cellular distribution of Nur77 was analyzed in the two cell lines. After a $3 \mathrm{~h}$ exposure to F23.1 antibodies the majority of D011.10 cells displayed a nuclear distribution of Nur77, as illustrated by a more intense red/pink staining in the nuclear region of the cell (Figure 5B, panel a, arrow indicates nuclear staining). However, in a large proportion of mutant 51 cells Nur77 remained in the cytoplasm suggesting a failure to import this transcription factor into the nucleus (Figure 5B, panel b; see arrow). Interestingly, PMA/A23187 caused a rather diffuse distribution of Nur77 throughout the nuclear and cytoplasmic regions in the majority of both DO11.10 and mutant 51 cells (Figure 5B, panels $\mathrm{c}$ and $\mathrm{d}$ respectively), illustrating further differences in the cellular signaling associated PMA/A23187 and TCR-mediated apoptosis.

\section{Mutant 51 cells demonstrates delayed Fas ligand (FasL) dependent killing and express reduced Fas receptor levels on their surface}

Mature T-cells undergo activation induced cell death via engagement of the Fas receptor by its ligand FasL while in T-cell hybridomas it has been shown that TCR-induced cell death is dependent on Fas/FasL. ${ }^{17}$ Therefore we examined the expression of Fas receptor and the cytotoxic activity of FasL by DO11.10 and mutant 51 cells. A cellular based functional assay was used to determine killing activity of FasL. It was found that there was a clear delay in the onset and subsequent induction of FasL mediated killing by mutant 51 cells, as assessed by chromium release from target cells expressing the Fas receptor (Figure 6A).

Analysis of Fas levels demonstrated there was a $90 \%$ reduction of surface Fas expression on mutant 51 cells as measured by FACS analysis in comparison to DO11.10 cells (Figure 6B). However, at a concentration of Jo2 antiFas antibody $(10 \mu \mathrm{g} / \mathrm{ml})$ that induced apoptosis in greater than $80 \%$ of mouse thymocytes (data not shown) no cell death of DO11.0 or mutant 51 was seen by dye exclusion after $18 \mathrm{~h}$ incubation (Figure 1). 
A
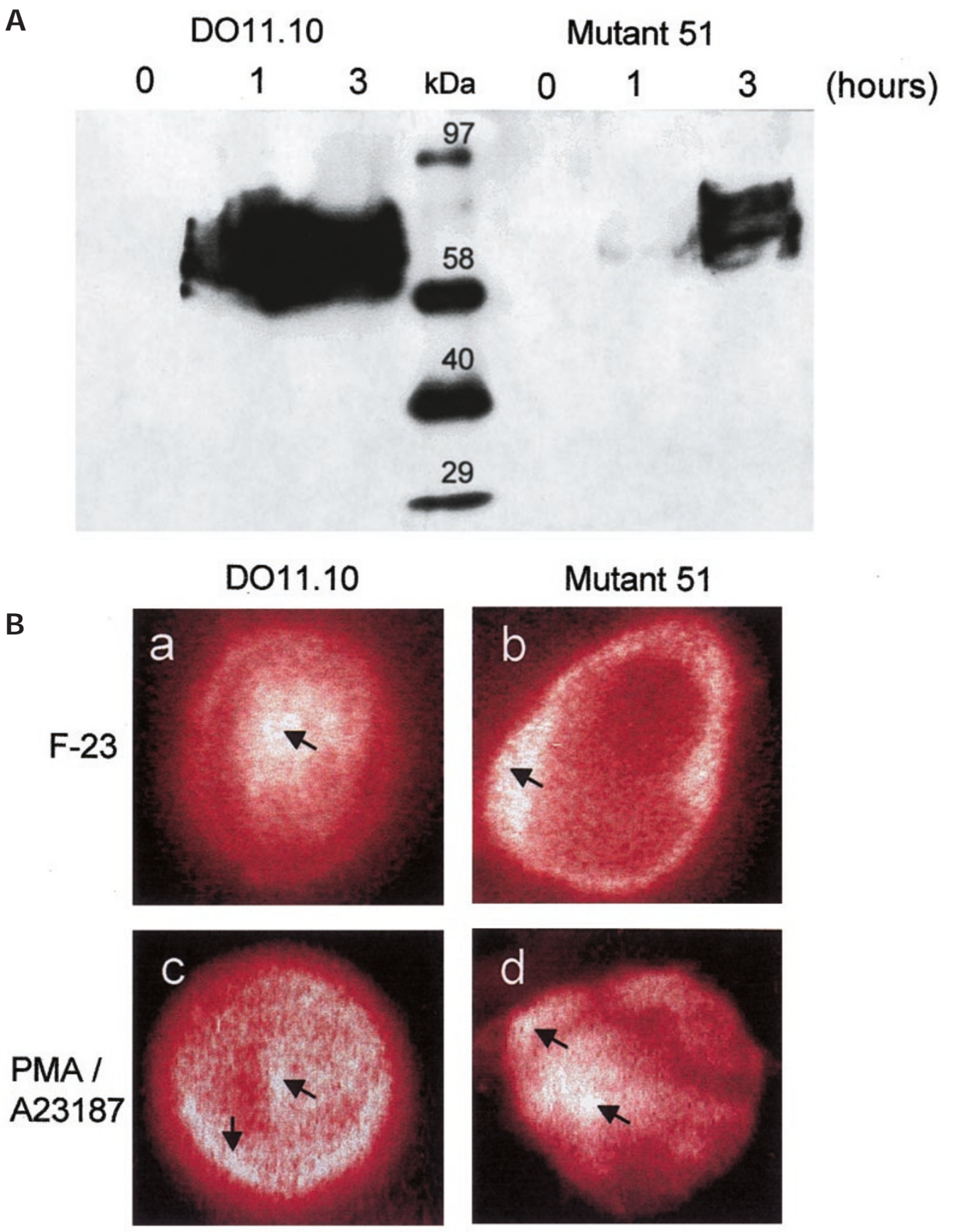

Figure 5 (A) Nur77 protein levels by Western blot analysis. $2 \times 10^{5}$ mutant 51 or D011.10 cells were exposed to F23.1 for various times before lysis in SDS sample buffer. Proteins were separated in a $8 \%$ polyacrylamide gel and transferred to nitrocellulose. Nur77 protein was detected using anti-Nur77 monoclonal antibody (1:1000 dilution) followed by sheep anti-mouse-HRP (1:4000). Immunodetection of proteins followed directions as described for chemiluminescence analysis using the ECL system (Amersham). (B) Cellular localization of Nur77 protein in DO11.10 and mutant 51 cells. $4 \times 10^{5} / \mathrm{ml}$ mutant 51 or DO11.10 cells were cultured on coverslips coated with F23.1 antibodies for $3 \mathrm{~h}$. The coverslips were then soaked in methanol before exposure to anti-Nur77 antibodies for 30 min at room temperature. After washing in PBS the cells were exposed to the secondary antibody conjugated to FITC for 30 min at room temperature. Following additional washing in PBS the cells were viewed under a UV microscope and representative images recorded. Panel (a) shows a representative DO11.10 cell after exposure to F23.1 antibodies for $3 \mathrm{~h}$ with mainly nuclear localization of Nur77 as demonstrated by more intense fluorescence. Panel (b) illustrates a representative mutant 51 cell after exposure to F23.1 antibodies for $3 \mathrm{~h}$ with the majority of Nur77 being localized to the cytoplasm. Panel (c) shows a DO11.10 cell after exposure to PMA and A23187 for $3 \mathrm{~h}$. Notice the more random distribution of Nur77 protein as indicated more intensely stained areas. Both cytoplasm and the nucleus appear to have localized Nur77. Panel (d) shows a mutant 51 cell following treatment with PMA and A23187 for $3 \mathrm{~h}$. As in Panel (c) a more random distribution of Nur77 protein is seen throughout the cell. Arrows indicate areas of intense staining. Color intensity is proportional to Nur77 levels and is shown in red for clarity. These examples are representative of the majority of cells viewed 
A

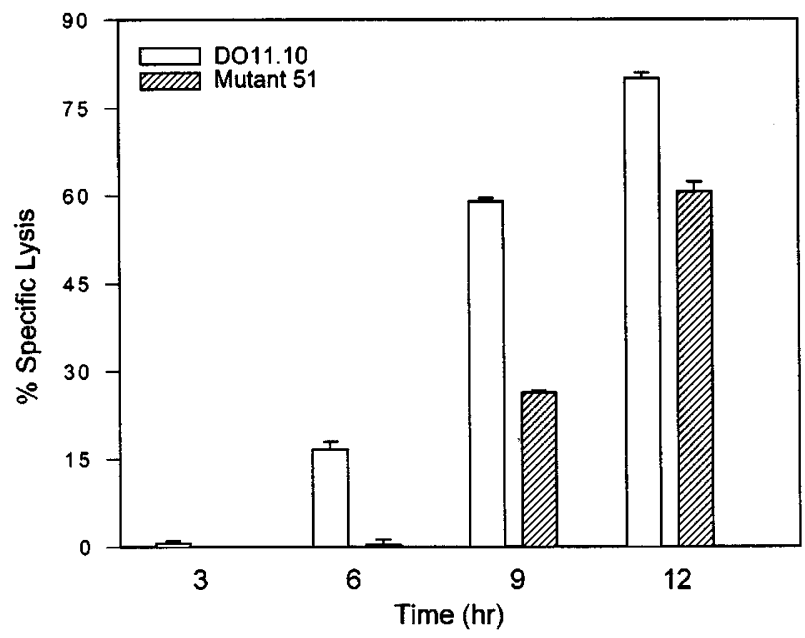

B

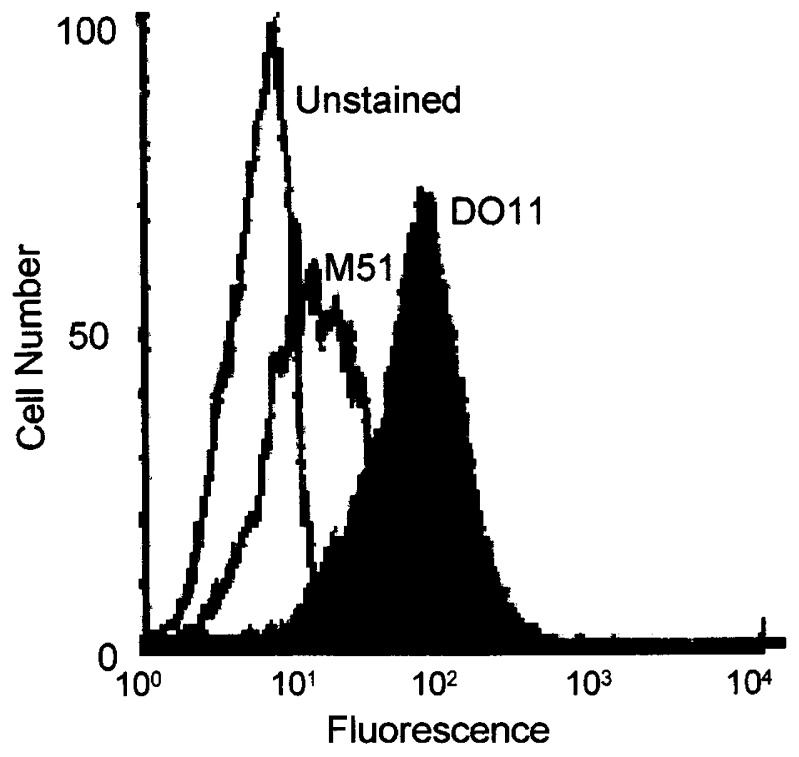

Figure 6 (A) Delayed induction of FasL cytotoxic activity in mutant 51 cells. Relative cytotoxic activity of D011.10 and mutant 51 cells was determined by co-culturing $3 \times 10^{6}$ effector cells with $3 \times 10^{5}{ }^{51} \mathrm{Cr}$-labeled LK target cells in the presence of $2.5 \mu \mathrm{g} / \mathrm{ml}$ anti-CD3 for various times. The anti-CD3 served to both activate the T-cells and facilitate conjugate formation. The level of ${ }^{51} \mathrm{Cr}$ release in co-cultures lacking the anti-CD3 was used to calculate spontaneous release (SR) for each time point. Per cent specific lysis was calculated according to the formula: (experimental c.p.m.$\mathrm{SR}$ )/maximum release-SR) $\times 100$. The data shown is the mean triplicate values $+/$ - s.e.m. and is representative of three comparable experiments (B) Fas receptor surface expression on mutant 51 and D011.10 cells $1 \times 10^{6}$ D011.10 and mutant 51 cells were incubated with Jo2-PE monoclonal anti-Fas receptor antibody $\left(1 \mu \mathrm{g} / 10^{6}\right.$ cells). Cells were incubated on ice for $1 \mathrm{~h}$ before washing and resuspension in $300 \mathrm{ml} 1 \%$ formalin in PBS and analyzed by FACScan. Results of the FACS data are presented as overlays of fluorescence from cells that were not incubated with Jo-PE (Unstained peak), mutant 51 cells conjugated to Jo-PE (M51 unfilled peak) and D011.10-Jo2-PE stained cells (D011 filled peak). Fluorescence is presented on a log scale. Results are representative of similar experiments

\section{Discussion}

In the thymus, corticosteroids and TCR engagement appear to provide antagonistic signals by a mechanism of molecular crosstalk, providing a sensitive balance between positive and negative selection in developing thymocytes. In support of this hypothesis, Ashwell ${ }^{29}$ and $\mathrm{King}^{30}$ demonstrated that these stimuli also down-regulate the others ability to induce apoptosis in vivo. Studies have shown that although the execution phase of cell death induced by these two signals (such as DNA breakdown and membrane blebbing) are similar, the upstream inductive phase depends upon unique, pathway dependent signaling molecules. ${ }^{5}$ To investigate in more detail the signaling molecules involved in TCR-induced cell death a T-cell hybridoma cell line was selected that did not undergo apoptosis in response to PMA and the calcium ionophore, A23187. Consistent with the proposed similarity between TCRmediated apoptosis and PMA/A23187 induced cell death, these mutant cells were also unable to die in response to TCR cross linking. In addition it was found that mutant 51 also had a diminished response to dexamethasone but was susceptible to $\gamma$ irradiation induced apoptosis, suggesting that the execution stage of apoptosis, shared between TCR, glucocorticoid and $\gamma$-irradiation-induced cell death was not defective. Therefore we investigated the ability of mutant 51 , in comparison to DO11.10 to mobilize calcium, an early second messenger known to be required for most forms of apoptosis. ${ }^{7}$

Direct evidence for the role of calcium in apoptosis comes from several groups who have shown that inhibition of the calcium rise by extra and intracellular calcium chelators prevents apoptosis ${ }^{6}$ and our unpublished data $\mathrm{GM})$. Apoptosis is also inhibited by cyclosporin A, a compound that is thought to inhibit calcium dependent signaling pathways by inactivating the calcium-dependent protein phosphatase calcineurin. ${ }^{12}$ Recently, Serafini and co-workers, ${ }^{31}$ identified two mutant mature $\mathrm{T}$ lymphocyte clones that were unable to proliferate in response to PMA and calcium ionophore. This group demonstrated that the mutant T-cell lines were defective in capacitative calcium entry but had comparable intracellular calcium stores to the parental line. In contrast, our studies clearly demonstrate that although capacitative entry is not diminished in mutant 51 , these cells have markedly reduced stores of calcium in the endoplasmic reticulum, the main site of $\mathrm{IP}_{3}$-dependent calcium release. This diminished calcium rise from the ER was however not due to reduced expression of the IP3R1. This is important in light of a recent report demonstrating that Jurkat T-cells deficient in the IP3 receptor were unable to die in response to TCR, dexamethasone or $\gamma$ irradiation. ${ }^{26}$ Indeed close examination of IP3R1 protein levels indicated that mutant 51 cells expressed slightly elevated levels in comparison to DO11.10 cells. Although no gross differences seem to be associated with this increased expression, mutant 51 cells have an accelerated doubling time that may be associated with this higher expression of IP3R1 protein (unpublished data). Therefore these data demonstrate that one of the earliest detectable defects in this mutant cell line is the reduced level of calcium in intracellular stores released during the inductive phase of apoptosis. 
Although calcium has been consistently demonstrated to be required for TCR-mediated apoptosis, the role of calcium in glucocorticoid-induced death remains controversial. Perrin-Wolff and colleagues have shown that capactiative calcium entry is required for glucocortocoidinduced thymocyte death, whereas Bian and co-workers demonstrated that dexamethasone-mediated apoptosis in the S49 T-cell hybridoma line induced only small cytoplasmic $\mathrm{Ca}^{2+}$ elevations and was independent of extracellular calcium. ${ }^{32,33}$ Our studies show that mutant 51 is more susceptible to dexamethasone-induced death than TCR-mediated apoptosis. Therefore either the glucocorticoid-mediated pathway may require less calcium for induction of death, or additional defects may be associated with the TCR signaling pathway. Interestingly, recent work by Dolmetsch and co-workers illustrated using B lymphocytes that both the amplitude and duration of the calcium signal directed the activation of distinct downstream transcription factors. ${ }^{34}$ Thus these two independent signaling pathways may require differing levels of calcium to trigger gene transcription associated with the final apoptotic outcome. Further, in the IP3R deficient Jurkat cells Jayaraman and Marks found that calcium release in dexamethasone treated cells occurred between 24-48 h following treatment rather than as an immediate rise as seen after TCR engagement. ${ }^{26}$ Therefore mutant 51 might be defective in the early release of calcium from endoplasmic stores but may more efficiently release calcium into the cytoplasm as a later effect of dexamethasone signaling.

As the greatest inhibition of death was through the TCRmediated pathway in mutant 51 , additional studies were carried out to determine if this clone may have other TCRmediated signaling defects. Engagement of the TCR results in apoptosis and the release of IL-2, both of which require the calcium dependent protein calcineurin. This protein targets a variety of transcription factors including NFAT (nuclear factor of activated T-cells). Upon dephosphorylation by calcineurin, NFAT translocates to the nucleus resulting in IL-2 gene transcription through the AP1 promotor. ${ }^{35}$ Mutant 51 cells were found to be defective in IL-2 secretion, most likely due to the reduced calcium stores available for calcineurin signaling. However, as supplementation of IL-2 to the cultures did not facilitate apoptosis in the mutant cells, the inability to die is not linked directly to the absence of IL-2 production. This is in agreement with previous studies showing that T-cell hybridomas could be induced to secrete IL-2 with or without apoptosis depending on the method of TCR stimulation. ${ }^{36}$ Consequently, although it has been shown using IL-2-deficient mice that they have reduced corticol thymocyte apoptosis and increased colitis-inducing thymocytes in their periphery, ${ }^{37}$ the less dramatic reduction of IL2 observed in mutant 51 is not directly responsible for the lack of apoptosis in mutant 51.

The majority of cell types investigated arrest in $\mathrm{G}_{1}$ of the cell division cycle prior to apoptosis. This accumulation in $\mathrm{G}_{1}$ is evident after TCR engagement, ${ }^{29}$ or glucocorticoid treatment. $^{38}$ However, after $\gamma$ irradiation, cells initially accumulate in $G_{2} / M$ before progressing to $G_{1} / G_{0}$ as they undergo the classic characteristics of apoptosis. ${ }^{39}$ In response to TCR engagement, these mutant cells failed to accumulate in any cell cycle phase and had a typical exponential population profile. Cell cycle arrest in $\mathrm{G}_{1}$ has been associated with accumulation of the immediate-early genes c-myc, c-fos and others. ${ }^{40}$ Myc expression is usually associated with the induction of proliferation associated genes in late $G_{1}$ but also accumulates in cells that are restricted to $G_{1}$ prior to apoptosis. ${ }^{41,42}$ The decision to proliferate or induce the apoptotic pathway appears to be regulated at least in part by collaboration between the immediate-early genes and survival- or death-inducing proteins. ${ }^{43}$ In addition, $\mathrm{Ca}^{2+}$ might also direct the signaling pathway taken by its levels and duration of the rise. ${ }^{34}$ As mutant cells stimulated through their TCR failed to accumulate in $G_{1}$ this may indicate a perturbance in immediate-early gene expression reuqired for PCD, possibly mediated via calcium regulation. Interestingly, mutant cells exposed to PMA and A23187 accumulated in both $G_{1}$ and $G_{2} / M$ suggesting that the direct action of calcium ionophore stimulated at least some immediateearly gene expression leading to cell cycle restriction. The fact that this $G_{1}$ accumulation was not associated with apoptosis suggests that additional factors or processes are required for the induction of cell death. This has been observed in other cell systems where cell cycle arrest did not predispose a cell to the apoptotic pathway. ${ }^{27}$

We and others have shown that TCR engagement of thymocytes or D011.10 hybridoma cells results in the up regulation of the immediate-early gene nur77, that was demonstrated to be absolutely required for TCR-mediated apoptosis. ${ }^{13,14}$ More recently it has been demonstrated that cyclosporin A blocks apoptosis in part by inhibiting the promoter activity, protein levels and down-regulating phosphorylation of Nur77.44 In some other cell types Nur77 is induced during proliferation, not apoptosis, and thus can also be associated with mitogenic signaling. ${ }^{45}$ Following translation, Nur77 protein is postranslationally modified by hyperphosphorylation. ${ }^{45}$ In the PC12 neuronal cell line, Nur77 is induced during proliferation and is differentially phosphorylated depending on growth factor treatment or membrane depolarization. This postranslation modification is therefore hypothesized to regulate the downstream signaling pathways initiated by Nur77 expression. ${ }^{46}$ Though the role of this additional phosphorylation in apoptosis is not known, it has been postulated to be required for nuclear localization and transcription of downstream apoptosis-associated genes. ${ }^{28}$ Previous studies with Nur77 in other non-lymphoid cell lines, have demonstrated nuclear localization of this protein during proliferation, whereas in other studies Nur77 appeared to be distributed throughout the cell. ${ }^{46,47}$ Therefore Nur77 may initiate numerous cellular outcomes depending on its localization and thus interaction with other signaling molecules. While Nur77 protein and phosphorylation levels were comparable in both mutant and the parental cells when stimulated through the TCR or with PMA and A23187, its expression was delayed and Nur77 protein failed to localize to the nucleus in the majority of mutant cells after TCR engagement. As Nur77 is both a 
transcription factor and a protein shown to be absolutely required for apoptosis in thymocytes and D011.10 cells, the lack of cell cycle arrest and death may in part be due to the lack of nuclear import of Nur77 in the mutant line. Interestingly, PMA + A23187 treatment caused Nur77 to distribute in both the nucleus and cytoplasm in both D011.10 and mutant 51 cells. This may be a result of the direct elevation of intracellular calcium levels by calcium ionophore, initiating partial nuclear localization of Nur77. This could also account for the cell cycle arrest seen in PMA/A23187 treated mutant cells and further suggests the requirement for additional factors other than cell cycle arrest and nuclear localization of Nur77 for the induction of death. Clearly these data indicate that, although both TCR engagement and PMA + A23187 cause comparable signaling processes to be activated, only the latter is able to overcome cell cycle defects in mutant 51 . Thus TCR-mediated signaling is uanble to initiate cell cycle restriction in mutant 51 whereas $\mathrm{PMA}+\mathrm{A} 23187$ can surmount this defect in the signaling pathway but is unable to overcome additional defects in the apoptotic machinery.

One of the downstream events associated with TCR engagement in both mature T-cells and T-cell hybridomas is the up-regulation of the Fas receptor. Fas engagement by its ligand is absolutely required for activation induced cell death in mature T-cells, apoptosis in T-cell hybridomas $^{17,48}$ and is also implicated in thymocyte negative selection. ${ }^{16,23}$ Mutant 51 cells expressed almost $90 \%$ less Fas receptor than the parental cell line, DO11.10, and had reduced ability to induce Fas ligandmediated cytotoxic killing of target cells. However, in our hands, engagement of the Fas receptor by anti-Fas antibodies, that caused rapid and extensive death in exvivo thymocytes (data not shown), was unable to induce death in either DO11.10 or the mutant clone. It therefore appears that TCR-mediated apoptosis requires Fas signaling, although direct engagement of the Fas receptor does not induce cell death in DO11.10. Taken together we hypothesize that mutant 51 may be resistant to TCR induced killing in part due to reduced Fas expression and/ or Fas ligand-dependent killing, although direct engagement of the Fas receptor, bypassing upstream TCR signaling, is unable to initiate apoptosis in either the parental or mutant clone. Additional studies are underway to determine to what extent, if any, downstream mediators of the Fas pathway play a role in TCR-mediated apoptosis in DO11.10 cells.

Here we present data outlining studies on a mutant T-cell hybridoma cell line with defects in TCR and glucocorticoid induced cell death. As the execution stage of the apoptosis signaling was most likely intact as suggested by the normal level of $\gamma$ irradiation induced cell death, this implicates a relatively early event following TCR engagement or glucocorticoid treatment. This was supported by the lack of cell cycle arrest in the mutant cells after TCR engagement and by the lack of IL-2 production. Further studies with mutant 51 demonstrated that calcium release from the ER was reduced, strongly suggesting that the absence of these early events associated with apoptosis is related to reduce calcium rises in the mutant cell line.
The lack of nuclear import of Nur77 may be a direct consequence of reduced calcium rises of may represent an independent aberration in this cell line. Regardless, it is appealing to postulate that deficient Nur77 nuclear localization and thus reduced direct or indirect transcription of downstream death-associated genes such as Fas, ${ }^{18}$ would reduce the degree of apoptosis observed. The lack of Fas and Fas ligand expression/function strongly supports this hypothesis. However, this must be tempered by the fact that PMA + A23187 causes partial nuclear localization and cell cycle arrest, but not apoptosis in this cell line. This clearly demonstrates that other factors, that may, or may not be mediated by calcium availability, are important for cell death in T-cell hybridomas in addition to Nur77 nuclear localization. The reduced death following dexamethasone treatment in mutant 51 supports this conclusion.

This T-cell hybridoma clone was selected on the basis of its resistence to PMA/A23187 induced apoptosis. Several defects have been identified that may contribute to the lack of TCR-mediated apoptosis in mutant 51 . Although these mutations may be due to one or several genetic abnormalities in mutant 51 , we can not rule out the possibility that this cell line represents founder cells that expressed an adaptive change at the cellular level in response to the environmental stress of selection. However, irrespective of the level at which this cell line displays cellular abnormalities, the characterization of mutant 51 has provided significant insights into the regulation of TCR-mediated apoptosis in T-cell hybridomas.

\section{Materials and Methods}

\section{Cells and cell culture conditions}

D011.10 cells were derived from the fusion of an immature T-cell line expressing a T-cell receptor (TCR) specific for ovalbumin peptide 323-329 and the T-cell thymoma BW5147. F23.1 hybridoma cells provided antibodies specific for the $\mathrm{V} \beta 8$ chain of the DO11.10 TCR. F23.1 supernatant was used without dilution for all F23.1 antibody experiments described. Cells were maintained in a 1:1 mix of RPMl and DMEM (Gibco) supplemented with $2 \mathrm{mM}$ glutamine, $20 \mu \mathrm{g} / \mathrm{ml}$ gentamicin, $1 \mathrm{~g} / \mathrm{ml}$ glucose and $10 \%$ heat inactivated $\left(56^{\circ} \mathrm{C}\right.$ for $\left.30 \mathrm{~min}\right)$ horse serum (Gibco). Cultures wre incubated at $37^{\circ} \mathrm{C}$ in a humidified atmosphere of $7 \% \mathrm{CO}_{2}$ in air. All derived mutant cells were maintained under similar conditions.

\section{Mutant cell selection procedure}

Exponentially growing D011.10 cells were exposed to $10 \mathrm{nM}$ phorbol myristic acetate (PMA; Sigma) and $500 \mathrm{nM}$ calcium ionophore (A23187; Sigma) and incubated at $37^{\circ} \mathrm{C}$. The majority, (>90\%) of D011.10 cells exposed to this regimen died with the first $24 \mathrm{~h}$ as assessed by trypan blue exclusion assay. After 2 days the cells were washed and similar levels of PMA and A23187 added before incubation at $37^{\circ} \mathrm{C}$. This procedure was repeated a further two times before surviving cells were single cell cloned. One such clone, mutant 51, was then expanded and re-selected in media supplemented with PMA + A23187 to reconfirm that this clone was resistant to death induced by these agents. 


\section{Stimulation of cells to die}

Log phase cells were induced to die either by the addition of $10 \mathrm{nM} \mathrm{PMA}+500 \mathrm{nM}$ A23187, or $10 \mu \mathrm{M}$ dexamethasone, or $30 \mathrm{~Gy}$ $\gamma$ irradiation, or $10 \mu \mathrm{g} \mathrm{Jo2} \mathrm{monoclonal} \mathrm{anti-Fas} \mathrm{receptor} \mathrm{antibody} / \mathrm{ml}$ (Pharmingen), or via the TCR using F23.1 antibodies. To do this, tissue culture plates or flasks were coated with $10 \mu \mathrm{g} / \mathrm{ml}$ sheep anti-mouse $\mathrm{Ig}$ in phosphate buffered saline (PBS; pH. 7.2) for $1 \mathrm{~h}$ at $37^{\circ} \mathrm{C}$, rinsed in PBS then incubated with F23.1 cell supernatant for $1 \mathrm{~h}$ at $37^{\circ} \mathrm{C}$. After washing with PBS the plate was ready for cells to be added. Mutant 51 or D011.10 cells were then added to the F23.1 coated plates or were treated with the above apoptosis inducing reagents before incubation at $37^{\circ} \mathrm{C}$ for $18 \mathrm{~h}$ in a humified atmosphere of $7 \% \mathrm{CO}_{2}$.

\section{Detection of death}

Cell death was determined using either fluorescein isothiocyanate (FITC; Sigma) or propidium iodide exclusion assays. Briefly, FITC was added to cells at $10 \mu \mathrm{g} / \mathrm{ml}$ and the cultures incubated in the dark for $15 \mathrm{~min}$ at $37^{\circ} \mathrm{C}$. Following washing with PBS the cells were fixed in $1 \%$ formalin and kept on ice in the dark until FACS analysis. Alternately, Yo-Pro (Molecular Probes) a fluorescent dye based on propidium iodide was added to cells at $1 \mu \mathrm{l} / \mathrm{ml}$ before placing on ice. Cells were analyzed immediately by FACScan analysis (Becton Dickenson) and lysis software.

\section{Detection of intracellular calcium changes}

Cells were washed in calcium free water (W1503; Sigma) supplemented with $155 \mathrm{mM} \mathrm{NaCl}$ (Sigma), $4.5 \mathrm{mM} \mathrm{KCl}$ (Sigma), $1 \mathrm{mM} \mathrm{MgCl} 2$ (Sigma), $10 \mathrm{mM}$ D-glucose (Sigma), $5 \mathrm{mM}$ HEPES ( $\mathrm{pH} 7.4$; Sigma) and $1 \%$ Horse Serum (v/v; Gibco) pre-dialyzed against $100 \times$ vol PBS containing $6 \mathrm{mM}$ EGTA. After washing, the pellet was re-suspended in this buffer to a final cell density of $4 \times 10^{5} / \mathrm{ml}$ before addition of $1 \mu \mathrm{l} / \mathrm{ml} 20 \%$ pluronic acid (Molecular Probes) and $1 \mu \mathrm{M}$ Fluo 3 (Molecular Probes). The flasks were then incubated at $37^{\circ} \mathrm{C}$ in the dark for $30 \mathrm{~min}$. Subsequent to removing the extracellular Fluo 3 by washing, the cell density was adjusted to $4 \times 10^{5} / \mathrm{ml}$ in the calcium free buffer and the cells were placed in the dark on ice. Immediately prior to FACScan analysis the samples were warmed to $37^{\circ} \mathrm{C}$ for $5 \mathrm{~min}$. For all experiments a base line calcium level was obtained for $45 \mathrm{~s}$ before addition of $1 \mu \mathrm{M}$ thapsigargin (Molecular Probes), followed by $2 \mathrm{mM} \mathrm{CaCl} 2$ after the induced calcium rise had returned to baseline levels.

\section{T-cell receptor surface expression}

Cells were washed in cold PBS $+0.1 \%$ bovine serum albumin (BSA; Sigma) $/ 0.1 \%$ sodium azide (Sigma) and resuspended in F23.1 supernatant before placing on ice for $30 \mathrm{~min}$. After washing twice with PBS/BSA/azide the pellet was resuspended in FITC-conjugated sheep anti-mouse Ig and incubated at room temperature for $30 \mathrm{~min}$. Cells were again washed before fixation in 1\% formalin and analysis on the FACScan (Becton Dickenson).

\section{Interleukin 2 release}

Secretion of Interleukin 2 (IL-2) in culture supernatant was detected using the Biosource International Cytoscreen Immunoassay kit (Biosource). $1 \times 10^{5}$ D011.10 or mutant 51 cells were stimulated with F23.1 antibodies or $10 \mathrm{nM}$ PMA $+500 \mathrm{nM} \mathrm{A23187}$ for $16 \mathrm{~h}$. The supernatants were collected and incubated with IL-2 antibodies for $2 \mathrm{~h}$ at $37^{\circ} \mathrm{C}$. Following treatment with a secondary antibody as outlined in the manufacturers instructions absorbency was read at $450 \mathrm{~nm}$ and IL$2 \mathrm{pg} / \mathrm{ml}$ calculated from a standard curve.

\section{Cell cycle analysis}

D011.10 or mutant 51 cells were stimulated with $10 \mathrm{nM}$ PMA and $500 \mathrm{nM} \mathrm{A} 23187$, or $\mathrm{F} 23.1$ for $6 \mathrm{~h}$ at $37^{\circ} \mathrm{C}$ before washing and fixing for population cell cycle distribution as described previously. ${ }^{49}$ Briefly, cells were washed and resuspended in $75 \%$ ethanol/5\% glycerol in PBS. After incubation overnight at $-20^{\circ} \mathrm{C}$ the fixed cells were washed twice in PBS before resuspension in PBS + 50 Units RNase (Worthington Biochemical Co.). The cells were incubated at $37^{\circ} \mathrm{C}$ for $2 \mathrm{~h}$ before addition of $50 \mu \mathrm{g} / \mathrm{ml}$ propidium iodide and placing on ice until use. DNA content was analyzed by FACScan (Becton Dickenson) at $488 \mathrm{~nm}$ using CELLFIT software.

\section{Detection of protein expression}

Lysates were prepared by washing the cells once with PBS before resuspending the pellet in loading buffer, (2\% SDS, $10 \%$ glycerol, $100 \mathrm{nM}$ DTT, $60 \mathrm{mM}$ Tris (pH 6.8) and $0.001 \%$ bromophenol blue). Following polyacrylamide gel electrophoresis of the proteins on tris/glycine denaturing gels the proteins were transferred to nitrocellulose (Amersham) by wetblot transfer (BioRad). Immunodetection of proteins followed directions as described for chemiluminescent analysis using the ECL system (Amersham).

\section{Immunocytochemical analysis of Nur77 distribution}

For TCR engagement studies cover slips were coated with $10 \mu \mathrm{g} / \mathrm{ml}$ sheep anti-mouse antibody for $1 \mathrm{~h}$ at $37^{\circ} \mathrm{C}$, washed once in PBS and then incubated in $\mathrm{F} 23.1$ antibody for $1 \mathrm{~h}$ at $37^{\circ} \mathrm{C}$. The cover slips were again washed in PBS before placing in a $100 \mathrm{~mm}$ petri dish with $5 \times 10^{5} / \mathrm{ml} \mathrm{DO11.10}$ or mutant 51 cells in growth medium. In other experiments $5 \times 10^{5} / \mathrm{ml} \mathrm{D011.10} \mathrm{or} \mathrm{mutant} 51$ were placed in $100 \mathrm{~nm}$ petri dishes with uncoated cover slips and $10 \mathrm{nM}$ PMA $+500 \mathrm{nM}$ A23187 in growth medium. After $3 \mathrm{~h}$ the cover slips were removed and placed into methanol precooled at $-20^{\circ} \mathrm{C}$ for $10 \mathrm{~min}$. The cells were washed in PBS/Tween $20(0.1 \% \mathrm{v} / \mathrm{v})$ before addition of $40 \mu \mathrm{l}$ monoclonal anti-Nur77 antibody (1:2 dilution PBS/0.1\% Tween $20 /$ $2 \% \mathrm{BSA}$ ) and incubated in a humid atmosphere for $18 \mathrm{~h}$ at room temperature. Cover slips were washed twice in PBS/Tween $20(0.1 \%)$ $\mathrm{v} / \mathrm{v}$ ) before addition of $40 \mu \mathrm{l}$ FITC conjugated sheep anti-mouse antibodies (diluted 1:128 in PBS/Tween 20/BSA). Cells were incubated for $30 \mathrm{~min}$ at room temperature before washing four times in PBS/Tween 20 and mounting on glass slides for visualization. Fluorescence was viewed using UV microscopy.

\section{Fas ligand cytotoxic activity}

$3 \times 10^{6}$ D011.10 or mutant 51 effector cells were co-cultured with $3 \times 10^{5}$ LK target cells labeled with Chromium 51 (effector: target ratio of $10: 1$ ), in the presence of $2.5 \mu \mathrm{g} / \mathrm{ml}$ anti-CD3 monoclonal antibody. The cells were incubated at $37^{\circ} \mathrm{C}$ for various times before measuring chromium release in the supernatant. ${ }^{50}$ Cultures that lacked anti-CD3 antibody were used to measure spontaneous release of chromium 51 . 


\section{Fas receptor expression}

$1 \times 10^{6}$ D011.10 and mutant 51 cells were centrifuged $(500 \mathrm{~g} / 5 \mathrm{~min})$ before resuspending in $200 \mu \mathrm{lPBS} / 0.1 \% \mathrm{BSA} / 0.1 \%$ azide with Jo2-PE monoclonal anti-Fas receptor antibody $\left(1 \mu \mathrm{g} / 10^{6}\right.$ cells; Pharmingen). Cells were incubated on ice for $1 \mathrm{~h}$ before washing in PBS/BSA/azide twice followed by one wash with PBS. The pellets were resuspended in $300 \mu \mathrm{l} 1 \%$ formalin in PBS and analyzed by FACScan.

\section{Acknowledgements}

We appreciate the critical review of the manuscript by Jennifer Trimble. In addition we thank Chang Li He for Western blot analysis of IP3R levels and Bret Verhoven for initial help with the project. GM was supported by a grant from the American Cancer Society (IM-759). This work was also funded by a grant from the National Institutes of Health to BAO (GM 47922).

\section{References}

1. Wyllie $A H$ (1980) Glucocorticoid induced thymocyte apoptosis is associated with endogenous endonuclease activation. Nature 284: 555-556

2. Smith CA, Williams GT, Kingston R, Jenkinson EJ and Owens JJT (1989) Antibodies to CD3 T-cell receptor complex induce death by apoptosis in immature T cells in thymic cultures. Nature 337: 181-184

3. Lowe SW, Schmitt EM, Smith SW, Osborne BA and Jacks T (1993) p53 is required for radiation-induced apoptosis in mouse thymocytes. Nature 362 : $847-849$

4. Sellins KS and Cohen JJ (1987) Gene induction by gamma-irradiation leads to DNA fragmentation in lymphocytes. J. Immunol. 139: 3199-3206

5. Osborne BA (1996) Apoptosis and the maintenance of homoeostasis in the immune system. Curr. Opin. Immunol. 8: 245-254

6. Vasquez NJ, Kane LP and Hedrick SM (1994) Intracellular signals that mediate thymic negative selection. Immunity 1: 45-56

7. McConkey DJ and Orrenius S (1996) The role of calcium in the regulation of apoptosis. J. Leukoc. Biol. 59: 775-783

8. McConkey DJ, Hartzel P, Duddy SK, Hakansson H and Orrenius S (1988) 2,3,7,8-tetrachlorodibenzo-p-dioxin kills immature thymocytes by $\mathrm{Ca}^{2+}$ mediated endonuclease activation. Science 242: 256-259

9. Sarin A, Adams DH and HenkartPA (1993) Protease inhibitors selectively blockT cell hybridoma and activated peripheral T cells. J. Exp. Med. 178: 1693-1700

10. Montague JW, Gaido ML, Frye C and Cidlowski JA (1994) A calcium-dependent nuclease from apoptotic rat thymocytes is homologous with cyclophilin Recombinant cyclphilins $A, B$, and $C$ have nuclease activity. J. Biol. Chem. 269: $18877-18880$

11. Hollander GA, Fruman DA, Bierer BE and Burakoff SJ (1994) Disruption of T cel development and repetoire selection by calcineurin inhibition in vivo. Transplantation 58: 1037-1043

12. Shi Y, Sahai B and Green D (1989) Cyclosporin A inhibits-induced cell death in Tcell hybridomas and thymocytes. Nature 339: 625-626

13. Liu ZG, Smith SW, McLaughlin KA, Schwartz LM and Osborne BA (1994) Apoptotic signals delivered through the T-cell receptor of a T-cell hybrid require the immediate-early gene nur77. Nature 367: 281-284

14. Woronicz JD, Calnan B, Ngo V and Winoto A (1994) Requirement for the orphan steroid receptor Nur77 in apoptosis of T-cell hybridomas. Nature 367: 277-281

15. Calnan BJ, Szychowski S, Chan FK-M, Cado D and Winoto A (1995) A role for the orphan steroid receptor nur77 in apoptosis accompanying antigen-induced negative selection. Immunity 3: 273-282

16. Dhein J, Walczak H, Baumler C, Debatin K-M and Krammer PH (1995) Autocrine T-cell suicide mediated by APO-1/Fas/CD95). Nature 373: 438-441

17. Ju S-T, Panka DJ, Cui H, Ettinger R, El-Kahtib M, Sherr DH, Stranger BZ and Marshak-Rothstein A (1995) Fas (CD95)/FasL interactions required for programmed cell death after T-cell activation. Nature 373: 444-448

18. Park CG, Lee SY, Kandala G, Lee SY and Choi Y (1996) A novel gene product that couples TCR signaling to Fas(CD95) expression in activation-induced cell death. Immunity 4: 583-591
19. Muzio M, Chinnaiyan AM, Kirschkel FC, O'Rourke K, Shevchenko A, Ni J, Scaffidi C, Bretz JD, Zhang M, Gentz R, Mann M, Krammer PH, Peter ME and Dixit VM (1996) FLICE, a novel FADD-homologues ICE/CED-3 like protease, is recruited to the CD95 (Fas/APO-1) death-inducing signaling complex. Cell 85: $817-827$

20. Enari M, Hug H and Nagata S (1995) Involvement of an ICE-like protease in Fasmediated apoptosis. Nature 375: 78-81

21. Los M, de Craen MV, Penning LC, SchenkH, Westendorp M, Baeuerle PA, Droge W, Krammer PH, Fiers W and Schulze-Osthoff K (1995) Requirement of an ICE/ CED-3 protease for Fas/APO-1-mediated apoptosis. Nature 375: 81-83

22. Watanabe-Fukunaga R, Brannan $\mathrm{Cl}$, Copeland NG, Jenkins NA and Nagata S (1992) Lymphoproliferation disorder in mice explained by defects in Fas antigen that mediates apoptosis. Nature 356: 314-317

23. Castro JE, Listman JA, Jacobson BA, Wang Y, Lopez PA, Ju S, Finn PW and Perkins DL (1996) Fas modulation of apoptosis during negative selection of thymocytes. Immunity 5: 617-627

24. Singer GG, Carrera AC, Marshak-Rothstein A, Martinez C and Abbas AK (1994) Apoptosis, Fas and systemic autoimmunity: the MRL-Ipr/lpr model. Curr. Opin. Immunol. 6: 913-920

25. Thastrup O, Cullen PJ, Drobak BK, Hanley MR and Dawson AP (1990) Thapsigargin, a tumor promoter, discharges intracellular $\mathrm{Ca2}+$ store by specific inhibition of the endoplasmic reticulum Ca2(+)-ATPase. Proc. Natl. Acad. Sci. USA 87: $2466-2470$

26. Jayaraman T and Marks AR (1997) T cells deficient in inositol 1,4,5trisphosphate receptor are resistant to apoptosis. Mol. Cell. Biol. 17:3005-3102

27. Deiss LP, Feinstein E, Berissi H, Cohen O and Kimichi A (1995) Identification of a novel serine/threonine kinase and a novel $15 \mathrm{kd}$ protein as potential mediators of the gamma interferon-induced cell death. Genes Dev. 9: 15-30

28. Carson Jurica MA, Schrader WT and O'Malley BW (1990) Steroid receptor family: Structure and functions. Endocr. Rev. 11: 201-220

29. Ashwell JD, Cunningham RE, Noguchi PD and Hernandez D (1987) Cell growth cycle block of T cell hybridomas upon activation with antigen. J. Exp. Med. 165: 173-194

30. King LB, Vacchio MS, Dixon K, Hunziker R, Margulies DH and Ashwell JD (1995) A targeted glucocorticoid receptor antisense transgene increases thymocyte apoptosis and alters thymocyte development. Immunity 3: 647-656

31. Serafini AT, Lewis RS, Clipstone NA, Fiering S, Herzenberg LA and Crabtree GR (1995) Isolation of mutant T lymphocytes with defects in capactiative calcium entry. Immunity 3: 239-250

32. Perrin-Wolff M, Bertoglio J, Bressac B, Bohuon C and Pallardy M (1995) Structure-activity relationships in glucocorticoid-induced apoptosis in $\mathrm{T}$ lymphocytes. Biochem. Pharmacol. 50: 103-110

33. Bian X, Hughes FMJ, Huang Y, Cidlowski JA and Putney JWJ (1997) Roles of cytoplasmic $\mathrm{Ca}^{2+}$ and intracellular $\mathrm{Ca}^{2+}$ stores in induction and suppression of apoptosis in S49 cells. Am. J. Physiol. 272: C1241-C1249

34. Dolmetsch RE, Lewis RS, Goodnow CC and Healy JI (1997) Differential activation of transcription factors induced by $\mathrm{Ca}^{2+}$ response amplitude and duration. Nature 386: 855-858

35. Ullman KS, Northrop JP, Verweij CL and Crabtree GR (1990) Transmission of signals from the $T$ lymphocyte antigen receptor to the genes responsible for cell proliferation and immune function: The missing link. Annu. Rev. Immunol. 8: $421-452$

36. Glickstein L, Macphil S and Stutman O (1996) Uncoupling IL-2 production from apoptosis and TNF production by changing the signal through the TCR. J. Immunol. 156: 2062-2067

37. Ludviksson BR, Gray B, Strober W and Ehrhardt RO (1997) Dysregulated intrathymic development in the IL-2-deficient mouse leads to colitis-inducing thymocytes. J. Immunol. 158: 104-111

38. Lanza L, M. S, Puppo F, Bosco O, Peirano L, Filaci G, Fecarotta E, Vidali G and Indiveri $F$ (1996) Prednisone increases apoptosis in in vitro activated human peripheral blood T lymphocytes. Clin. Exp. Immunol. 103: 482-490

39. Strasser A, Harris AW and Cory S (1994) DNA damage can induce apoptosis in proliferating lymphoid cells via p53-independent mechanisms inhibitable by Bcl2. Cell 79: $329-339$

40. Sukhatme VP (1990) Early transcriptional events in cell growth: the Egr family. J. Am. Soc. Nephrol. 1: 859-866

41. Evan GI, Wyllie AH, Gilbert CS, Littlewood TD, Land H, Brooks M, Walters CM, Penn LZ and Hancock DC (1992) Induction of apoptosis in fibroblasts by c-myc protein. Cell 69: 119-128 
42. Hoang AT, Cohen KJ, Barrett JF, Bergstrom DA and Dang CV (1994) Participation of cyclin A in Myc-induced apoptosis. Proc. Natl. Acad. Sci. USA 91: 6875-6879

43. Kaufmann-Zeh A, Rodriquez-Viciana P, Ulrich E, Gilbert C, Coffer P, Downward J and Evan G (1997) Suppression of c-Myc-induced apoptosis by Ras signalling through $\mathrm{PI}(3) \mathrm{K}$ and PKB. Nature 385: 544-548

44. YazdanbakhshK, ChoiJ-W, LiY, Lau LF and Choi Y (1995) Cyclosporin A blocks apoptosis by inhibiting the DNA binding activity of the transcription factor Nur77. Proc. Natl. Acad. Sci. USA 92: 437-441

45. Hazel TG, Misra R, Davis IJ, Greenberg ME and Lau LF (1991) Nur77 is differentially modified in PC12 cells upon membrane depolarization and growth factor treatment. Mol. Cell. Biol. 11: $3239-3246$

46. Fahrner T, Carroll SL and Milbrandt J (1990) The NGFI-B protein, an inducible member of the thyroid/steroid receptor family, is rapidly modified posttranslationally. Mol. Cell. Biol. 10: 6454-6459
47. Ryseck RP, MacDonald Bravo H, Mattei MG, Ruppert S and Bravo R (1989) Structure, mapping and expression of a growth factor inducible gene encoding a putative nuclear hormonal binding receptor. EMBO J. 8: 3327-3335

48. Wong B, Arron J and Choi Y (1997) T cell receptor signals enhance susceptibility to Fas-mediated apoptosis. J. Exp. Med. 186: 1939-1944

49. Morgan GA, Laufman HB, Otieno-Omondi FP and Black SJ (1993) Control of G to $S$ cell cycle progression of Trypanosoma brucei S427cl1 organisms under axenic conditions. Mol. Biochem. Parasitol. 57: 241-252

50. Brunner KT, Mauel J, Cerottini J-C and Chapuis B (1968) Quantitative assay of the lytic action of immune lymphoid cells on ${ }^{51} \mathrm{Cr}$ labeled allogenic target cells in vitro: Inhibition by isoantibody and by drugs. Immunology 14 $181-196$ 